OPEN ACCESS

Edited by:

Francois Galgani,

French Research Institute for Exploitation of the Sea (Ifremer),

France

Reviewed by:

Stefano Aliani,

National Research Council, Italy

Olivia Gerigny,

French Research Institute for Exploitation of the Sea (Ifremer),

France

*Correspondence:

Britta D. Hardesty

denise.hardesty@csiro.au

Specialty section:

This article was submitted to

Marine Pollution

a section of the journal

Frontiers in Marine Science

Received: 01 November 2016

Accepted: 25 January 2017

Published: 31 March 2017

Citation:

Hardesty BD, Harari J, Isobe A Lebreton L, Maximenko N, Potemra J,

van Sebille $E$, Vethaak $A D$ and Wilcox C (2017) Using Numerical Model Simulations to Improve the Understanding of Micro-plastic Distribution and Pathways in the

Marine Environment.

Front. Mar. Sci. 4:30.

doi: 10.3389/fmars.2017.00030

\section{Using Numerical Model Simulations to Improve the Understanding of Micro-plastic Distribution and Pathways in the Marine Environment}

\author{
Britta D. Hardesty ${ }^{1 *}$, Joseph Harari ${ }^{2}$, Atsuhiko Isobe $^{3}$, Laurent Lebreton ${ }^{4,5}$, \\ Nikolai Maximenko ${ }^{6}$, Jim Potemra ${ }^{6}$, Erik van Sebille ${ }^{7}$, A. Dick Vethaak ${ }^{8,9}$ and Chris Wilcox ${ }^{1}$ \\ ${ }^{1}$ Commonwealth Scientific and Research Organization, Oceans and Atmosphere, Hobart, TAS, Australia, ${ }^{2}$ Department of \\ Physical, Chemical and Geological Oceanography, Oceanographic Institute, São Paulo University, São Paulo, Brazil, ${ }^{3}$ Centre \\ for Oceanic and Atmospheric Research, Research Institute for Applied Mechanics, Kyushu University, Fukuoka, Japan, ${ }^{4}$ The \\ Modelling House Ltd., Wellington, New Zealand, ${ }^{5}$ The Ocean Cleanup Foundation, Delft, Netherlands, ${ }^{6}$ International Pacific \\ Research Center, School of Ocean and Earth Science and Technology, University of Hawaii, Honolulu, HI, USA, ${ }^{7}$ Grantham \\ Institute and Department of Physics, Imperial College London, London, UK, ${ }^{8}$ Deltares, Marine and Coastal Systems, Delft, \\ Netherlands, ${ }^{9}$ Department of Chemistry and Biology, Institute for Environmental Studies, Vrije Universiteit Amsterdam, \\ Amsterdam, Netherlands
}

Numerical modeling is one of the key tools with which we can gain insight into the distribution of marine litter, especially micro-plastics. Over the past decade, a series of numerical simulations have been constructed that specifically target floating marine litter, based on ocean models of various complexity. Some of these models include the effects of currents, waves, and wind as well as a series of processes that impact how particles interact with ocean currents, including fragmentation and degradation. Here, we give an overview of these models, including their spatial and temporal resolution, limitations, availability, and what we have learned from them. Then we focus on floating marine micro-plastics ( $<5 \mathrm{~mm}$ diameter) and we make recommendations for experimental research efforts that can improve the skill of the models by increasing our understanding of the processes that govern the dispersion of marine litter. In addition, we highlight the importance of knowing accurately the sources or entry points of marine plastic debris, including potential sources that have not been incorporated in previous studies (e.g., atmospheric contributions). Finally, we identify information gaps and priority work areas for research. We also highlight the need for appreciating and acknowledging the uncertainty that persists regarding the movement, transportation and accumulation of anthropogenic litter in the marine environment.

Keywords: accumulation modeling, fluxes, fragmentation, marine debris, microplastics, numerical modeling

\section{INTRODUCTION}

Pollution from marine plastic is a global issue of international concern. Marine litter comes from both land- and sea-based sources and can travel immense distances. Marine ecosystems worldwide are affected by human-made refuse, much of which is plastic (see Table 1 of Derraik, 2002). Resolving the biodiversity, environmental, economic, transport, navigation, and biological invasion hazards associated with anthropogenic litter in the marine environment requires a 
substantial, sustained integrated effort from individuals, industry, governments, and international governmental organizations at local to regional and global scales. The increase in global plastic production and the recent estimate of $\sim 8$ million metric tons of mismanaged plastic waste entering the ocean each year (Jambeck et al., 2015) points to the need to tackle the problem at a multitude of scales. There is no single solution, rather, a number of local and regional solutions will be required to effect change.

A necessary first step in addressing this problem is to get an estimate of the amount of plastic in the oceans, including knowledge about from where it originates, where it is accumulating, and the pathways by which it got there. This is a complex problem for a variety of reasons, including challenges in sampling both in situ (in the water column, sediments, etc.) and at the source (e.g., riverine input, coastal input, sea-surface input, etc.). Sampling micro-plastic is particularly and challenging since it is not easily observed due to its small size, its sources include not only direct inputs but it also results from the degradation of larger plastic pieces. Furthermore, organisms can alter the pathways in the marine environment by direct transport and/or altering the density of the particles.

For these reasons, a mass budget of micro-plastic debris will be challenging to construct based on empirical data alone. Instead, simulations using numerical models of ocean currents may be used to estimate the sources, sinks, and pathways of micro-plastic in the marine environment. This approach of integrating models predicting debris flows and distributions has been useful in extending the existing sparse observations to make estimates of budgets in some parts of the system, and flows of mass in a few cases (Cózar et al., 2014; van Sebille et al., 2015; others). Extending this approach of integrating simulation models and empirical observations can greatly improve our understanding of plastics, and particularly micro-plastics, in the marine environment at a systems level.

\section{BACKGROUND}

Marine debris or marine litter is defined as any persistent, manufactured, or processed solid material discarded, disposed of or abandoned in the marine and coastal environment (UN Environment Program, 2009). Some portion of plastic litter may reach microscopic sizes due to degradation (mechanical forces and/or photochemical processes) of macro-plastic debris (Gigault et al., 2016) or is already manufactured as microscopic particles. These are referred to here as micro-plastics. This aspect of marine litter is of special interest as its physical properties allow it to be transported over large distances and its small size makes it available for a wide range of marine biota (Ivar do Sul et al., 2014; GESAMP, 2016). Its small size, however, makes it difficult to observe remotely, thus limiting an accurate assessment of total amounts. Nevertheless, plastic debris can be observed in seas around the world, from concentrations exceeding 600,000 pieces per $\mathrm{km}^{2}$ (Law et al., 2010) in the accumulation zones to more remote regions such as the waters of the Arctic (Bergmann et al., 2016) and the Antarctic (Barnes et al., 2010) where far fewer plastic pieces are observed. It has become clear that humanity's discarded litter is spreading throughout our seas and oceans (e.g., Pham et al., 2014; Jambeck et al., 2015; GESAMP, 2016).

Debris sampling and monitoring in the environment is most often carried out along the shoreline, but can also take place at sea or through sampling wildlife that have encountered debris. Most often, monitoring and surveys of litter take place in coastal regions, often as part of clean up activities or other community events. Using information from these activities as monitoring information raises a number of issues, as the activities can be idiosyncratic, may have uneven sampling, and frequently do not control sampling effort carefully. Designed surveys can provide much more robust data, however, these are much rarer globally [but see OSPAR (http://www.ospar.org/work-areas/ eiha/marine-litter), CSIRO (http://www.csiro.au/en/Research/ OandA/Areas/Marine-resources-and-industries/Marine-debris; Hardesty et al., 2016), and NOAA's (https://marinedebris.noaa. gov/) approaches].

Debris, especially plastics, can also be surveyed in the ocean, although coastal and high seas monitoring can be expensive and difficult to replicate. Typically, oceanic monitoring of marine litter takes place through surface trawl sampling, which is biased toward items within a particular size range-those that are small enough to fit in the mouth of the net, large enough to be stopped by the net mesh, are floating on or near the ocean's surface and can be and discerned by the human eye (see van Sebille et al., 2015; typically in the range between 0.25 and $0.0003 \mathrm{~m}$ ). Surface sampling captures floating objects only and, given the vastness of the ocean, complex, and ever changing ocean circulation patterns and wind mixing, samples are often highly variable. At-sea sampling also requires large sample sizes to facilitate the statistical analysis required to detect potential changes in distribution and abundance, given the high spatial and temporal heterogeneity of marine litter, especially plastics in the ocean (Barnes et al., 2009).

Nearly all of the plastic (95\% or more of the items or particles by count) recorded from surface trawl sampling efforts are smaller than $5 \mathrm{~mm}$ in diameter. Similarly, these smaller items make up the vast majority of debris found in coastal samples-at least for surveys that record smaller sizes of items (Hardesty et al., 2016). Because of technological challenges, however, field studies so far have only been able to analyse the large and middle-sized micro-plastics (>20 micrometer; Galgani et al., 2013). Hence, our discussion focuses on the distribution and movement of the fraction of floating micro-plastics in the ocean in this size range, from 5 to $0.02 \mathrm{~mm}$ in diameter.

\section{How Much (Micro) Plastic Is in the Ocean?}

There are a number of questions that remain unanswered regarding micro-plastic in the ocean. These questions are also valid for plastic in general, since it can be a major contributing source of micro-plastic. Perhaps the most straightforward, fundamental question is how much plastic is in the ocean? While recent work quantified plastic inputs from land into the ocean (Jambeck et al., 2015), the amount (whether by weight or volume) in the global ocean remains poorly understood, and estimates vary with orders of magnitude. Additional questions that fall 
under this key knowledge gap involve understanding what are the sources, where micro-plastic occurs in the ocean, what its size spectra are, and how much there is in various locations around the globe. Identifying the contributing sources and sinks (where it comes from and where it ends up) as well as recognizing the proportion of micro-plastic that is from primary vs. secondary (e.g., breakdown) sources are key questions which inform our understanding of how much plastic is in the ocean. In essence, to address this fundamental question of the total load we need to better understand the sources, pathways and fate of (micro) plastic.

\section{What Are the Main Contributing Sources of Plastic in the Ocean?}

Approximately $80 \%$ of the plastic in the oceans is estimated to come from land-based sources or entry points (Sheavly and Register, 2007; Galgani et al., 2013) which includes beaches, rivers, stormwater runoff, aquaculture and fisheries, shipping transport, and atmospheric outfall (see GESAMP, 2016). Debris sampling, correspondingly, largely takes place via coastal activities and is likely biased by larger items that are easily discernible by the human eye. Primary microplastics, however, are often abrasives or similar purpose-produced small, regular sized particles and may be missed due to issues of visual detection.

We know relatively little about the proportion of microplastics entering the marine environment as primary versus secondary microplastics (resulting from the breakdown of larger items). However, it is reasonable to presume that the breakdown or transition of larger plastics to micro-plastics may be most common in the nearshore environment, due to the high energy of the coastal environment and the presence of other natural abrasives such as sand and rock. Further adding to the challenge of quantifying and identifying sources of microplastics is that many microplastics such as fibers are negatively buoyant and are therefore missed by most sampling methods. In sediment cores (and invertebrates) for example, fibers are common (Besseling et al., 2012; Woodall et al., 2014). However, most coastal and offshore microplastics sampling takes place in the upper surface of the ocean and hence samples positively buoyant items. As a result, our knowledge of sources of microplastics is affected by biased sampling, and most modeling to date is on the buoyant fraction of plastics in the ocean.

\section{How Does Plastic Move in the Ocean?}

The various factors that contribute to the pathways of microplastic in the ocean are an active area of research. Quantitative estimates of losses (and budgets) would fundamentally be improved with a more complete understanding of how microplastics move in the environment. Researchers are working on mesocosm or other small-scale experiments in the laboratory to look at wave action, fouling, and other aspects that affect movement (Gerritse et al., 2015; Fazey and Ryan, 2016a,b; ter Halle et al., 2016), but such exercises are relatively new and have yet to be applied at larger scales. There is a clear niche for experimental work in improving our understanding of plastic movement and the use of local, regional, and global models can significantly also significantly contribute to improving our understanding of the issue (see Table $\mathbf{1}$ for some of the available ocean circulation models and oceanographic datasets used for marine debris modeling/tracking).

\section{What is the Fate of Plastic in the Ocean?}

Considering the fate of micro-plastic in the ocean requires improving our understanding of where plastic persists in reservoirs and what the rates of fragmentation are under various conditions (and for various material and sizes of primary plastic). Better estimates and data describing buoyancy, i.e., sinking and re-suspension or floating rates will also yield insights to the fate of plastics in the ocean. Furthermore, knowing the distribution of plastic and whether it ends up in locations where it can be removed or in places where it can break down to smaller pieces and/or re-enter the ocean will greatly inform the question of how much plastic is in the ocean.

\section{CURRENT ASSESSMENT}

Long term monitoring of micro-plastic abundance is costly, time consuming, and difficult to sustain. Importantly, however, though there are a number of long term monitoring efforts on coastlines, such as OSPAR's marine beach litter program in Europe (http://www.ospar.org), the International Coastal Cleanup (ICC) which is organized by the Ocean Conservancy (http://www.oceanconservancy.org) and NOAA's marine debris program which monitors coastal litter using multiple monitoring approaches (http://www.marinedebris.noaa.gov). These long term initiatives are important not only to detect long term trends and patterns in terms of coastal debris, but it can also allow one to evaluate the efficacy of legislation, to identify changes in sources, deposition, material types and potential impacts to wildlife. Furthermore, long term monitoring can help to identify opportunities for impact through local actions. Each of these initiatives, however, focuses on larger sized items ( $>5 \mathrm{~mm}$ ) which means that they are useful in detecting likely sources of secondary micro-plastic quantities, types, and locations for point of entry to the marine environment, but such efforts fail to report on primary micro-plastic amounts, density, and changes through time.

Around the world, there are a number of different data collection strategies that have been developed and employed to monitor marine and coastal litter. While it is important to recognize that different questions require different monitoring approaches, the importance of standardization of approaches cannot be overstated (Barnes et al., 2009; e.g., does one report counts or weight or by surface area or volume?). To date, global harmonization of monitoring methods and data recording have remained unrealized, but working toward this remains an important goal (Cheshire et al., 2009; Galgani et al., 2013). Recently, the importance of global harmonization of monitoring methods are recognized by increasing number of scientists; see the Annex to Leaders' Declaration of Elmau G7 summit (http://www.mofa.go.jp/mofaj/files/000084023.pdf) and the Communique of G7 Toyama Environment Ministers' Meeting (http://www.env.go.jp/press/files/jp/102871.pdf). 
TABLE 1 | Some available ocean circulation models and oceanographic datasets used for marine debris modeling/tracking.

\begin{tabular}{|c|c|c|}
\hline Model/dataset & Description & References \\
\hline BLUELink & $\begin{array}{l}\text { CSIRO Ocean modeling and analysis tool used for accurately forecasting ocean } \\
\text { conditions }\end{array}$ & Wilcox et al., 2013 \\
\hline Connie2 & Australian Connectivity Interface, web-tool developed by CSIRO & Reisser et al., 2013 \\
\hline ECCO & $\begin{array}{l}\text { Estimation of Circulation and Climate of the Ocean-Scripps Institution of } \\
\text { Oceanography (SIO), the NASA Jet Propulsion Laboratory (JPL) and the Massachusetts } \\
\text { Institute of Technology (MIT) }\end{array}$ & Potemra, 2012 \\
\hline ECMWF ORA-S3 & $\begin{array}{l}\text { Ocean analysis/reanalysis system of European Center for Medium-Range Weather } \\
\text { Forecasts (ECMWF) }\end{array}$ & Potemra, 2012 \\
\hline Global drifter program & $\begin{array}{l}\text { Satellite-tracked surface drifting buoy observations of currents, sea surface temperature, } \\
\text { atmospheric pressure, winds, and salinity (NOAA) }\end{array}$ & $\begin{array}{l}\text { Maximenko et al., 2012; van Sebille et al., 2012; } \\
\text { Reisser et al., } 2013\end{array}$ \\
\hline GNOME & $\begin{array}{l}\text { General NOAA Operational Model Environment; interactive simulation system designed } \\
\text { for modeling pollutant trajectories in marine environment }\end{array}$ & GNOME User's Manual, 2002 \\
\hline HYCOM & $\begin{array}{l}\text { Hybrid Co-ordinate Model-forced by US Navy's Operational Global Atmospheric } \\
\text { Prediction System (NOGAPS) }\end{array}$ & $\begin{array}{l}\text { Lebreton et al., 2012; Potemra, 2012; Lebreton } \\
\text { and Borrero, } 2013\end{array}$ \\
\hline NCOM & $1 / 8^{\circ}$ global Navy Coastal Ocean Model (NAVOCEANO) - real time & Potemra, 2012 \\
\hline NEMO & Nucleus for European Modeling of the Ocean & Storkey et al., 2010 \\
\hline NLOM & $\begin{array}{l}1 / 32^{\circ} \text { global Navy Layered Ocean Model run daily by the Naval Oceanographic Office } \\
\text { (NAVOCEANO) - real time }\end{array}$ & Potemra, 2012 \\
\hline OSCAR & Ocean Surface Current Analysis - Real time (NOAA) & Martinez et al., 2009 \\
\hline OSCURS & Ocean Current Simulator Model (NOAA Fisheries Service) & $\begin{array}{l}\text { Ebbesmeyer and Ingraham, 1994; Ebbesmeyer } \\
\text { et al., } 2012\end{array}$ \\
\hline PELET-2D & Lagrangian particle tracking model (Helmholtz-Zentrum Geesthacht) & Neumann et al., 2014 \\
\hline plasticadrift.org & Web-tool developed by E. van Sebille based on trajectories of Global surface drifters & van Sebille, 2014 \\
\hline Pol3DD & Lagrangian 3-D numerical dispersal model & Lebreton et al., 2012; Lebreton and Borrero, 2013 \\
\hline SCUD & Surface Currents from Diagnostics - developed by International Pacific Research Centre & Maximenko and Hafner, 2010 \\
\hline SODA & Simple Ocean Data Assimilation model (by Cummings et al., 2005) & Potemra, 2012 \\
\hline
\end{tabular}

Sustained monitoring is crucial to assess the efficacy of measures implemented to reduce the abundance of plastic debris, but it is complicated by large spatial and temporal heterogeneity in the amounts of plastic debris and by our limited understanding of the pathways followed by plastic debris and its long-term fate. Thus far, most monitoring has focused on beach surveys of stranded plastics and other litter, as mentioned above. Infrequent surveys of the standing stock of litter on beaches provide crude estimates of debris types and abundance, but are biased by differential removal of litter items by beachcombing, clean-ups and beach dynamics. However, there is increased sampling of and analyses of micro-plastics on the ocean's surface (Reisser et al., 2013; Cózar et al., 2014; Eriksen et al., 2014; Isobe et al., 2015; Ryan, 2015; van Sebille et al., 2015) with fewer studies reporting on sub-surface micro-plastics (but see Reisser et al., 2015; Kooi et al., 2016).

\section{Reservoirs: Where Is Micro-plastic Found?}

Plastic has been found throughout, the ocean from the surface, all the way through the water column to the deep ocean floor. It can reside in sediment, biota, and ice, and may be trapped along the coastline or in estuaries, waterways and lakes, and can even be suspended in the atmosphere (Dris et al., 2016; GESAMP, 2016). There is no reason to believe the presence of micro-plastic is any less wide-spread.

In this study, we divide locations into seven broad categories deemed most relevant for modeling movement of plastics in

\section{RESERVOIRS \& FLUXES}

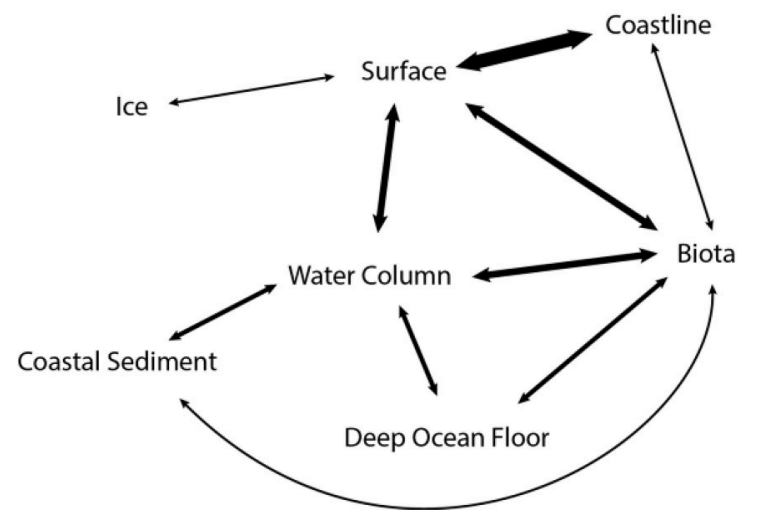

FIGURE 1 | Schematic representation of reservoirs and fluxes for marine plastics. The weight of the arrow indicates the magnitude of marine debris flux hypothesized to occur between compartments, and the fluxes or flows between them.

the ocean: surface, coastline/estuaries, ocean floor, sediments, ice, biota, and water column (Figures 1, 2). While there are other reservoirs (e.g., the atmosphere, lakes, and waterways), we consider those to fall outside of the scope and focus of this paper. For our purposes they are considered as sources of micro-plastics entering the ocean. 


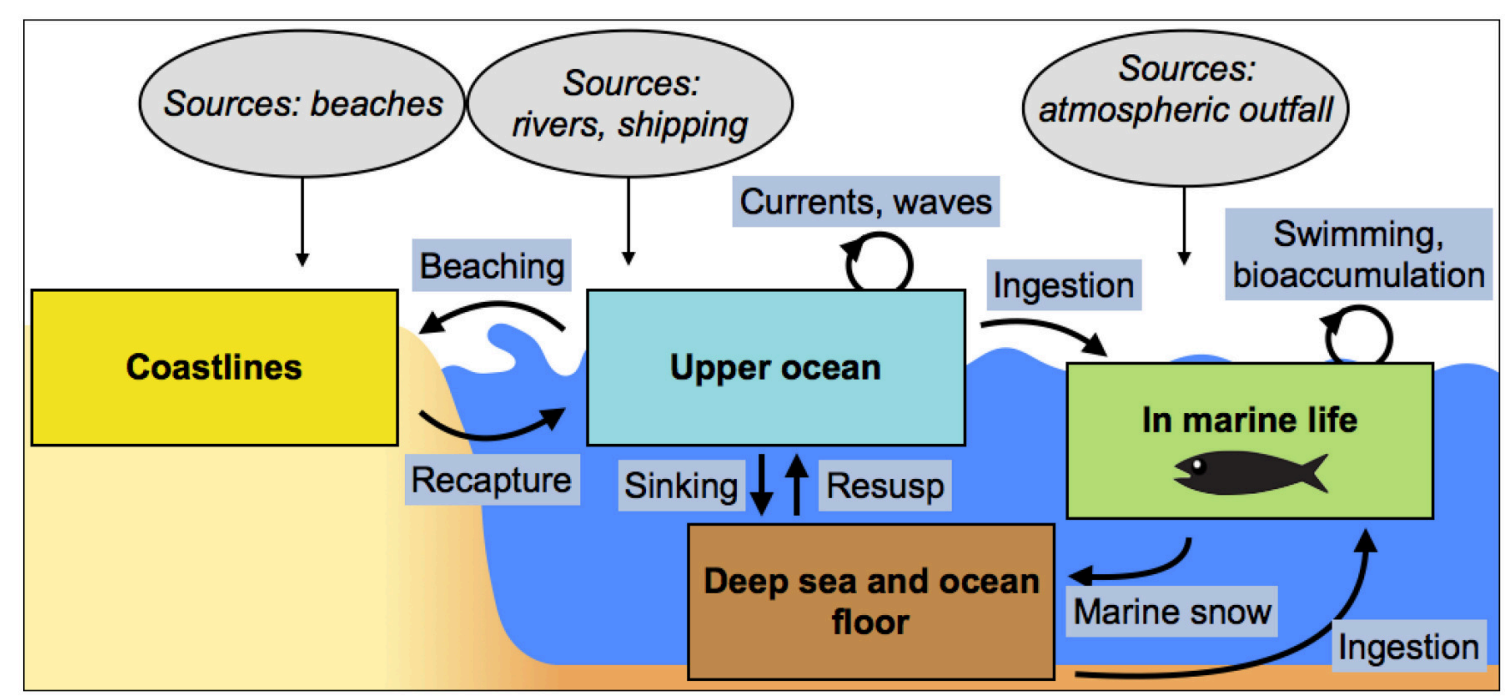

FIGURE 2 | The sources of anthropogenic debris entering the ocean (ovals), reservoirs, or oceanic compartments where debris occurs (boxes) and processes through which debris moves between compartments.

Evaluating budgets (sources and sinks into the environment) or leakage between these reservoirs or compartments requires understanding several key processes. Those deemed to be particularly important include rates of fragmentation, buoyancy/sinking/re-floating rates, as well as the rates and quantities of inputs of litter to the ocean and time trends for plastics in ocean.

When assessing the potential reservoirs of micro-plastic it is equally important to understand the uncertainty bounds. Identifying in which reservoirs there is the greatest uncertainty will facilitate a ranking of transitions on which efforts could be focused, taking into account the key question at hand (whether that relates to sources, losses between transition zones or impacts).

\section{THE APPLICATION OF NUMERICAL MODELING}

Overall, there are two ultimate goals to improve our modeling of plastic budgets and impacts of marine debris. Identifying where, how and why plastic enters (and leaves) the ocean is very different from understanding the biodiversity, economic, and environmental impact plastic is having in the marine environment. One difference is that the former (understanding the budget) requires modeling of the mass of plastic, while the latter (understanding the impacts) requires modeling the number of plastic particles. In this paper, we focus on understanding the budget.

\section{Modeling Key Fluxes}

There are three main fluxes that are considered here to be of highest priority (Figure 1). These include the fluxes that occur between the ocean and the coast; movements between the coast to ocean interface; and the fluxes between the ocean (whether surface, water column, or floor) and biota (and the other direction). The first two are considered most important since the near-shore environment is where most plastic must pass through to reach the open ocean. This is also a zone of high biodiversity and hence, where much of the biological impact is likely to occur.

This does not rule out the importance of movement between oceanic reservoirs or movement between the surface and water column. Rather it highlights the critical need for better understanding of movement between key reservoirs. Fluxes between ice and other reservoirs were considered to be of lesser importance, though there is agreement among oceanographers that modeling fluxes between ice and other reservoirs may not be particularly difficult.

Both for a mass balance modeling approach and to evaluate impacts, understanding of the accumulation of plastic in biota is needed. Importantly, this is a "sink" (and can act as a transport mechanism) where empirical data can be collected-whether through analysis of seabirds digestive tracts or fish guts or total body analysis of invertebrates, through excreta, or with noninvasive sampling techniques. There is a growth in the number of papers reporting on the interactions between plastics and marine fauna (see Gall and Thompson, 2015), with ingestion of debris, entanglement, and chemical contamination increasingly reported in the literature. It might now be reasonable to estimate micro-plastics residing in marine biota, but to date, an estimate of the overall mass of debris in wildlife (much less focusing on micro-plastics has yet to be carried out.

\section{Needed Improvements}

The marine debris problem can be viewed as a source, pathway and sink issue. Simulations using numerical models can be important tools in estimating or constraining any of these three when the other two are more well-known. Simulations can also be 
used to test hypotheses addressing knowledge gaps within these three. Given the challenges of monitoring micro-plastic both before it arrives and once it is already in the marine environment, combining empirical data, and modeling approaches can be useful to help predict, or forecast, where micro-plastics occur in the marine environment.

Numerical modeling has been applied to track back or hindcast from where plastics in the ocean may have come (sensu; Kako et al., 2011), and these same approaches could be used for micro-plastic. Hindcasting is particularly useful for source identification, especially where accumulation regions have been identified. Ocean circulation models can further be used to identify where oceanic accumulation zones are most likely to occur. Coupling such tools and approaches with species distribution maps and other ecological information, we can combine disparate data types to predict or identify hotpots of risk to taxa or geographic regions of interest (Schuyler et al., 2013, 2015; Wilcox et al., 2015, 2016). We can also identify movement pathways or trajectories (Wilcox et al., 2013), identify hotspots, and develop scenario analysis tools to identify potential sources and sinks. We can further evaluate effectiveness of local actions and activities (see Hardesty et al., 2016), predict risk of invasion along pathways and evaluate costs of inaction and efficiency of action (Sherman and Van Sebille, 2016).

Modeling efforts have greatly improved in recent years, and as computing power increases, so too does our ability to incorporate additional parameters into simulating marine debris movement in the ocean. In addition to circulation models that provide estimates of ocean currents, there are other models that can be employed, including for example, risk models and bioaccumulation models (ecosystem scale modeling). Each has a relevant role to play in increasing our knowledge and understanding of marine litter transport, and the development and employment of different modeling approaches depends upon the questions asked, the region studied, and the overall aim of the research.
Currently, knowledge on plastic in the oceans is insufficient to accurately estimate the total plastic budget and we are unable to measure ocean (micro) plastic directly at scale. Modeling allows us to make estimates and predictions outside of where we have data and facilitates our ability to run process studies. With models we can focus on major drivers at a global scale and potentially can scale these down to consider local processes. There currently exist global data on wind, tides, waves, pressure, and other processes that are identified as critically important. The challenge is how to bring these typically coarse data sets down to the coastal or finer scales and thus apply them to improve our understanding of the factors that drive debris movement at regional and local scales. While there may be some loss in resolution through such scaling to consider smaller geographic regions, these approaches will nevertheless improve our ability to map risk-and impact-to marine biota, regions, and ecosystems.

There is a big gap between presently used ocean circulation models, commonly having $10-\mathrm{km}$ horizontal and $10-\mathrm{m}$ vertical resolution (see Table 2), and operational activities that would require $10-\mathrm{m}$ details or even finer. Enhancement of numerical models to this fine grid would also require $O(1 \mathrm{~mm})$ vertical resolution and $O(1 \mathrm{~s})$ temporal resolution. With the exponentially growing computer power, high-resolution computation may become possible in some decades. However, it will require development of principally new models that include processes that are poorly understood today: e.g., momentum injection by breaking wind waves, diurnal cycle in the ocean and atmosphere boundary layers, etc. It is likely that such models will have to use the full-complexity "primitive" equations and will have to be coupled rather than forced models.

Forcing of the models will require a new generation of the global observing system [currently monitoring the ocean at $O(100 \mathrm{~km})$ resolution], designing satellite missions that can measure smaller debris (currently available at $30 \mathrm{~cm}$ resolution), measuring surface currents, as well as three-dimensional datasets incorporating bottom and land topography.

TABLE 2 | Transfers from reservoirs to reservoirs, with the approaches required to increase our understanding and improve models.

\begin{tabular}{|c|c|c|c|c|c|c|c|}
\hline & Surface & Ocean floor & Sediment & Ice & Biota & Coastline & Water column \\
\hline Surface & $\begin{array}{l}\text { Lagrangian modeling, } \\
\text { field tracking exper }\end{array}$ & $\begin{array}{l}\text { Lab exper/modeling/ } \\
\text { empirical }\end{array}$ & - & $\begin{array}{l}\text { Modeling/Field } \\
\text { measure }\end{array}$ & $\begin{array}{l}\text { Field measure/ } \\
\text { Spatial analysis }\end{array}$ & Lab and field exper & $\begin{array}{l}\text { Lab exper/ } \\
\text { modeling/empirical }\end{array}$ \\
\hline $\begin{array}{l}\text { Ocean } \\
\text { floor }\end{array}$ & (Lab and Field exper) & Field exper & Lab/field exper & Field exper & Empirical sampling & - & Lab/field exper \\
\hline Sediment & - & $\begin{array}{l}\text { Field sampling of ocean } \\
\text { floor sediments }\end{array}$ & - & Field exper & Lab exper & $\begin{array}{l}\text { Monitoring/ } \\
\text { sampling of } \\
\text { sediment cores }\end{array}$ & Modeling/exper \\
\hline Ice & Modeling & - & - & $\begin{array}{l}\text { Modeling/Field } \\
\text { obs }\end{array}$ & Field obs & Field obs & Modeling \\
\hline Biota & Lab/field & $\begin{array}{l}\text { Lab/field/Spatial } \\
\text { analysis }\end{array}$ & $\begin{array}{l}\text { Lab/field/Spatial } \\
\text { analysis }\end{array}$ & Field obs & Field/lab/modeling & $\begin{array}{l}\text { Lab/field/Spatial } \\
\text { analysis }\end{array}$ & $\begin{array}{l}\text { Lab/field/Spatial } \\
\text { analysis }\end{array}$ \\
\hline Coastline & Field, Modeling & - & $\begin{array}{l}\text { Coastline Monitoring } \\
\text { for sediments }\end{array}$ & - & Field/lab/modeling & Field/lab/modeling & Field/lab/modeling \\
\hline $\begin{array}{l}\text { Water } \\
\text { column }\end{array}$ & Lab/modeling & Lab/modeling & Lab/modeling & Field obs & Field/lab/modeling & - & $\begin{array}{l}\text { Lagrangian } \\
\text { modeling, field } \\
\text { tracking exper }\end{array}$ \\
\hline
\end{tabular}

Dashes indicate a lack of direct interaction between compartments (e.g., movement takes place through an intervening reservoir; see Figure 1). 
Further, information about marine debris (sources, composition, fragmentation, fouling, sinks, etc.) will also be needed at the corresponding space-time resolution. Highresolution modeling can be done in selected regions but, because of the open boundary conditions and Lagrangian dynamics of the debris, these regions can't be small.

Nested modeling, cascading from relatively coarse resolution in the open ocean to fine resolution near critical locations may optimize the use of resources. While the greater the resolution is needed to include important dynamics, the importance of acknowledging the significant contributions to be made with coarser resolution (both vertically and horizontally) cannot be overstated.

Tracing plastics back to their sources is often highlighted by researchers and policy makers as critical. This can be difficult in part due to variability between and within regions, which is often greater than realized. Models can, however, be tuned to consider empirical data collected in various regions (e.g., incorporating country, region or basin specific inputs, waste mismanagement and other covariates). Even in the absence of complete data (e.g., information from all regions), including sparse or incomplete data can still prove valuable.

Overlapping spatial mapping of marine litter (i.e., from accumulation models) with species distributions, vulnerable species or environmental sensitivity maps facilitates our ability to quantify the risk of plastics to biodiversity and marine ecosystems (see Hardesty and Wilcox, 2017). Dynamically modeling the risk or impacts becomes critically important not only for individuals and populations, but also for marine species that are exposed to multiple threats to survival and persistence. Identifying key geographic regions and taxa at higher or lower threat from marine plastics (e.g., Schuyler et al., 2015; Wilcox et al., 2015) can provide a useful lever to drive policy.

Where possible, researchers should aim to validate models with independent data. Independent validation of models can be used to not only increase model utility and confidence in results, but also increases our understanding of uncertainty. Quantifying, and indeed, acknowledging uncertainty in model solutions can help identify research opportunities and key knowledge gaps. Validating models against empirical data may also yield greater insights to processes, highlight regions or taxa of greater (or less than) predicted risk, provide additional opportunities for policy impact, as well as improve model calibration.

\section{KEY CHALLENGES AND OPPORTUNITIES}

Presently, many current simulations conserve the total number of particles (e.g., there is no loss, as in the adrift framework; van Sebille, 2014). To improve on this, parameterizations of key processes such as sinking and fragmentation rates will be needed. Appropriate data will be required in order to develop these parameterizations. Furthermore, there are data gaps leading to limitations in simulations due to areas with no or poor drifter data. Additionally, many simulations employed include surface drifters only, thereby missing subsurface movement.

One of the first and most significant improvements would be to add a loss term to look at losses in the environment.
One large uncertainty is in the rate of suspension/resuspension off/on shore. Can we establish a reasonable loss term for coastal regions? If so, what would be required? Adding a loss term would be an improvement and having data from standing stock surveys to look at the Coast-Ocean-Coast (C-O-C) suspension and resuspension would be critical.

To address the C-O-C knowledge gap, one way forward would be to have a transfer function from the coast to ocean and back again. Perhaps the best way to incorporate this into existing models is to find locations where there are long term data of coastline litter stocks. However, most coastal debris or clean up data focuses on macro rather than micro debris. Analysing such an empirical data set, coupled with relevant covariates (wind speed, direction, tides, etc.) would be useful. The ideal data set would be a long time series with frequent sampling intervals.

We further suggest that understanding marine micro-plastic movement would benefit from models that incorporate wind, waves, tides, data on rate, or frequency of active biofouling, and the rates of fragmentation and the processes leading to increased or decreased fragmentation (e.g., solar radiation; Isobe et al., 2014). To improve our knowledge modeling efforts would ideally be able to draw on a comprehensive list of datasets. These data sets would be geographically dispersed, long term, and with a high frequency of data collection.

\section{CONCLUSIONS}

Our understanding of litter sources, fate and movement is rapidly advancing. This is an exciting time in marine debris research as it is a growing speciality that can adapt, integrate and benefit from learning from other related research areas. While there remain a number of knowledge gaps with respect to marine litter modeling, there are significant advancements that can be, and are being, made in our understanding. Importantly, many of these advancements are being applied to underpin and inform policy and decision making at several scales, and we are seeing an increase in a collaborative approach to addressing the issue. While global plastic production continues unabated, the public's interest in and appetite for engagement through volunteering and citizen science can provide both broad and deep opportunities for data collection, high quality modeling, outreach, and behavioral change.

\section{AUTHOR CONTRIBUTIONS}

All authors listed, have made substantial, direct and intellectual contribution to the work, and approved it for publication.

\section{ACKNOWLEDGMENTS}

The ideas from this paper stemmed from the 2015 Modeling and Monitoring marine plastic workshops supported by the United Nations Environment Programme and CSIRO's Oceans and Atmosphere through the project 'Global Partnership on 
Marine Litter; Out of sight, out of mind? Changing the state of marine litter globally.' We thank Heidi Savelli and Peter Kershaw for their thoughtful comments, insights and contributions. NM was partly supported by the NASA Ocean Surface Topography
Science Team and the PICES ADRIFT Project Team; AI was supported by the Environmental Research and Technology Development Fund (4-1502) of the Ministry of the Environment, Japan.

\section{REFERENCES}

Barnes, D. K., Galgani, F., Thompson, R. C., and Barlaz, M. (2009). Accumulation and fragmentation of plastic debris in global environments. Philos. Trans. $R$. Soc. Lond. B. Biol. Sci. 364, 1985-1998. doi: 10.1098/rstb.2008.0205

Barnes, D. K., Walters, A., and Gonçalves, L. (2010). Macroplastics at sea around Antarctica. Mar. Environ. Res. 70, 250-252. doi: 10.1016/j.marenvres.2010.05.006

Bergmann, M., Sandhop, N., Schewe, I., and D'Hert, D. (2016). Observations of floating anthropogenic litter in the Barents Sea and Fram Strait, Arctic. Polar Biol. 39, 553-560. doi: 10.1007/s00300-015-1795-8

Besseling, E., Wegner, A., Foekema, E. M., van den Heuvel-Greve, M. J., and Koelmans, A. A. (2012). Effects of microplastic on fitness and PCB bioaccumulation by the lugworm Arenicola marina (L.). Environ. Sci. Technol. 47, 593-600. doi: 10.1021/es302763x

Cheshire, A., Adler, E., Barbière, J., Cohen, Y., Evans, S., Jarayabhand, S., et al. (2009). UNEP/IOC Guidelines on Survey and Monitoring of Marine Litter.

Cózar, A., Echevarría, F., González-Gordillo, J. I., Irigoien, X., Úbeda, B., Hernández-León, S., et al. (2014). Plastic debris in the open ocean. Proc. Natl. Acad. Sci. U.S.A. 111, 10239-10244. doi: 10.1073/pnas.1314705111

Cummings, J. A. (2005). Operational multivariate ocean data assimilation. Q. J. R. Meteorol. Soc. 131, 3583-3604.

Derraik, J. G. B. (2002). The pollution of the marine environment by plastic debris: a review. Mar. Pollut. Bull. 44, 842-852 doi: 10.1016/S0025-326X(02)00220-5

Dris, R., Gasperi, J., Saad, M., Mirande, C., and Tassin, B. (2016). Synthetic fibers in atmospheric fallout: a source of microplastics in the environment? Mar. Pollut. Bull. 104, 290-293. doi: 10.1016/j.marpolbul.2016.01.006

Ebbesmeyer, C. C., and Ingraham, W. J. (1994). Pacific toy spill fuels ocean current pathways research. EOS 75, 425-430. doi: 10.1029/94EO01056

Ebbesmeyer, C. C., Ingraham, W. J., Jones, J. A., and Donohue, M. J. (2012). Marine debris from the Oregon Dungeness crab fishery recovered in the Northwestern Hawaiian Islands: identification and oceanic drift paths. Mar. Pollut. Bull. 65, 69-75. doi: 10.1016/j.marpolbul.2011.09.037

Eriksen, M., Lebreton, L. C., Carson, H. S., Thiel, M., Moore, C. J., Borerro, J. C., et al. (2014). Plastic pollution in the world's oceans: more than 5 trillion plastic pieces weighing over 250,000 tons afloat at sea. PLoS ONE 9:e111913. doi: 10.1371/journal.pone.0111913

Fazey, F. M. C., and Ryan, P. G. (2016a). Debris size and buoyancy influence the dispersal distance of stranded litter. Mar. Pollut. Bull. 110, 371-377. doi: 10.1016/j.marpolbul.2016.06.039

Fazey, F. M. C., and Ryan, P. G. (2016b). Biofouling on buoyant marine plastics: an experimental study into the effect of size on surface longevity. Environ. Pollut. 210, 354-360. doi: 10.1016/j.envpol.2016.01.026

Galgani, F., Hanke, G., Werner, S., and De Vrees, L. (2013). Marine litter within the European marine strategy framework directive. ICES J. Mar. Sci. 70, 1055-1064. doi: $10.1093 /$ icesjms/fst122

Gall, S. C., and Thompson, R. C. (2015). The impact of debris on marine life. Mar. Pollut. Bull. 92, 170-179. doi: 10.1016/j.marpolbul.2014.12.041

Gerritse, J., Leslie, H., and Vethaak, D. (2015). Fragmentation of plastic litter in the marine environment our plastic-littered seas and how they transition from 'extra chunky' soup to a plastic 'bouillon'. Coastal and Marine. The CLEANSEA Project: An Interdisciplinary Study of Marine Litter in the EU. The Coastal and Marine Union (EUCC) Vol. 24, 14. Available online at: http://www.cleanseaproject.eu/drupal/sites/default/files/Coastalandmarine.pdf

GESAMP (2016). "Sources, fate and effects of microplastics $\mathrm{n}$ the marine environment: part two of a global assessment," in IMO/FAO/UNESCOIOC/UNIDO/WMO/IAEA/UN/UNEP/UNDP Joint Group of Experts on the Scientific Aspects of Marine Environmental Protection, Report Studies GESAMP No 93, eds P. J. Kershaw and C. M. Rochman, 220.
Gigault, J., Pedrono, B., Maxit, B., and Ter Halle, A. (2016). Marine plastic litter: the unanalyzed nano-fraction. Environ. Sci. 3, 346-350. doi: 10.1039/c6en00008h

GNOME User's Manual (2002). Available online at: http://response.restoration. noaa.gov/sites/default/files/GNOME_Manual.pdf

Hardesty, B. D., Lawson, T. J., van der Velde, T., Lansdell, M., and Wilcox, C. (2016). Estimating quantities and sources of marine debris at a continental scale. Front. Ecol. Environ. 15, 18-25. doi: 10.1002/fee.1447

Hardesty, B. D., and Wilcox, C. (2017). A risk framework for tackling marine debris. Anal. Methods 9, 1429-1436. doi: 10.1039/C6AY02934E

Isobe, A., Kubo, K., Tamura, Y., Kako, S., Nakashima, E., and Fujii, N. (2014). Selective transport of microplastics and mesoplastics by drifting in coastal waters. Mar. Pollut. Bull. 89, 324-330. doi: 10.1016/j.marpolbul.2014.09.041

Isobe, A., Uchida, K., Tokai, T., and Iwasaki, S. (2015). East Asian seas: a hot spot of pelagic microplastics. Mar. Pollut. Bull. 101, 618-623. doi: 10.1016/j.marpolbul.2015.10.042

Ivar do Sul, J. A., Costa, M. F., Silva-Cavalcanti, J. S., and Araújo, M. C. (2014). Plastic debris retention and exportation by a mangrove forest patch. Mar. Pollut. Bull. 78, 252-257. doi: 10.1016/j.marpolbul.2013.11.011

Jambeck, J. R., Geyer, R., Wilcox, C., Siegler, T. R., Rerryman, M., Andrady, A., et al. (2015). Plastic waste inputs from land into the ocean. Science 347, 768-771. doi: 10.1126/science.1260352

Kako, S., Isobe, A., Magome, S., Hinata, H., Seino, S., and Kozima, A. (2011). Establishment of numerical beach litter hindcast/forecast models: an application to Goto Islands, Japan. Mar. Pollut. Bull. 62, 293-302. doi: 10.1016/j.marpolbul.2010.10.011

Kooi, M., Reisser, J., Slat, B., Ferrari, F. F., Schmid, M. S., Cunsolo, S., et al. (2016). The effect of particle properties on the depth profile of buoyant plastics in the ocean. Sci. Rep. 6:33882. doi: 10.1038/srep33882

Law, K. L., Morét-Ferguson, S., Maximenko, N. A., Proskurowski, G., Peacock, E. E., Hafner, J., et al. (2010). Plastic accumulation in the North Atlantic subtropical gyre. Science 329, 1185-1188. doi: 10.1126/science.1192321

Lebreton, L. C. M., and Borrero, J. C. (2013). Modeling the transport and accumulation floating debris generated by the 11 March 2011 Tohoku tsunami. Mar. Pollut. Bull. 66, 53-58. doi: 10.1016/j.marpolbul.2012.11.013

Lebreton, L. C.-M., Greer, S. D., and Borerro, J. C. (2012). Numerical modelling of floating debris in the world's oceans. Mar. Pollut. Bull. 64, 653-661. doi: 10.1016/j.marpolbul.2011.10.027

Martinez, E., Maamaatuaiahutapu, K., and Taillandier, V. (2009). Floating marine debris surface drift: convergence and accumulation toward the South Pacific subtropical gyre. Mar. Pollut. Bull. 58, 1347-1355. doi: 10.1016/j.marpolbul.2009.04.022

Maximenko, N. A., and Hafner, J. (2010). SCUD: Surface Currents from Diagnostic Model. IPRC Tech. Note 5, 17. Available online at: http://apdrc.soest.hawaii.edu/projects/SCUD/SCUD_manual_02_17.pdf

Maximenko, N. A., Hafner, J., and Niiler, P. P. (2012). Pathways of marine debris derived from trajectories of Lagrangian drifters. Mar. Pollut. Bull. 65, 51-62. doi: 10.1016/j.marpolbul.2011.04.016

Neumann, D., Callies, U., and Matthies, M. (2014). Marine litter ensemble transport simulations in the southern North Sea. Mar. Pollut. Bull. 86, 219-228. doi: 10.1016/j.marpolbul.2014.07.016

Pham, C. K., Ramirez-Llodra, E., Alt, C. H., Amaro, T., Bergmann, M., Canals, M., et al. (2014). Marine litter distribution and density in European seas, from the shelves to deep basins. PLoS ONE 9:e95839. doi: 10.1371/journal.pone.0095839

Potemra, J. T. (2012). Numerical modeling with application to tracking marine debris. Mar. Pollut. Bull. 65, 42-50. doi: 10.1016/j.marpolbul.2011.06.026

Reisser, J., Shaw, J., Wilcox, C., Hardesty, B. D., Proietti, M., Thums, M., et al. (2013). Marine plastic pollution in waters around Australia: characteristics, concentrations, and pathways. PLoS ONE 8:e80466. doi: 10.1371/journal.pone.0080466 
Reisser, J., Slat, B., Noble, K., du Plessis, K., Epp, M., Proietti, M., et al. (2015). The vertical distribution of buoyant plastics at sea Biogeosciences 12, 1249-1256. doi: 10.5194/bg-12-1249-2015

Ryan, P. G. (2015). Does size and buoyancy affect the longdistance transport of floating debris? Environ. Res. Lett. 10:084018. doi: 10.1088/1748-9326/10/8/084019

Schuyler, Q. A., Wilcox, C., Townsend, K. A., Wedemeyer-Strombel, K. R., Balazs, G., van Sebille, E., et al. (2015). Risk analysis reveals global hotspots for marine debris ingestion by sea turtles. Glob. Change Biol. 22, 567-576. doi: $10.1111 /$ gcb.13078

Schuyler, Q., Hardesty, B. D., Wilcox, C., and Townsend, K. (2013). A global analysis of anthropogenic debris ingestion by sea turtles. Conserv. Biol. 28, 129-139. doi: 10.1111/cobi.12126

Sheavly, S. B., and Register, K. M. (2007). Marine debris \& plastics: environmental concerns, sources, impacts and solutions. J. Polym. Environ. 15, 301-305. doi: 10.1007/s10924-007-0074-3

Sherman, P., and Van Sebille, E. (2016). Modeling marine surface microplastic transport to assess optimal removal locations. Environ. Res. Lett. 11:014006. doi: 10.1088/1748-9326/11/1/014006

Storkey, D., Blockley, E. W., Furner, R., Guiavarc'h, C., Lea, D., Martin, M. J., et al. (2010). Forecasting the ocean state using NEMO: the new FOAM system. J. Oper. Oceanogr. 3, 3-15. doi: 10.1080/1755876X.2010.11020109

ter Halle, A., Ladirat, L., Gendre, X., Goudouneche, D., Pusineri, C., Routaboul, C., et al. (2016). Understanding the fragmentation pattern of marine plastic debris. Environ. Sci. Technol. 50, 5668-5675. doi: 10.1021/acs.est.6b00594

UN Environment Program (2009) Marine Litter. A Global Challenge. Nairobi: UNEP.

van Sebille, E. (2014). Adrift.org.au - a free, quick and easy tool to quantitatively study planktonic surface drift in the global ocean. J. Exp. Mar. Biol. Ecol. 461, 317-322. doi: 10.1016/j.jembe.2014.09.002

van Sebille, E., England, M. H., and Froyland, G. (2012). Origin, dynamics and evolution of ocean garbage patches from observed surface drifters. Environ. Res. Lett. 7:044040. doi: 10.1088/1748-9326/7/4/044040 van Sebille, E., Wilcox, C., Lebreton, L., Maximenko, N., Hardesty, B. D., Van Franeker, J. A., et al. (2015). A global inventory of small floating plastic debris. Environ. Res. Lett. 10:124006. doi: 10.1088/1748-9326/10/12/ 124006

Wilcox, C., Hardesty, B. D., Sharples, R., Griffin, D. A., Lawson, T. J., and Gunn, R. (2013). Ghostnet impacts on globally threatened turtles, a spatial risk analysis for northern Australia. Conserv. Lett. 6, 247-254. doi: 10.1111/conl. 12001

Wilcox, C., Mallos, N. J., Leonard, G. H., Rodriguez, A., and Hardesty, B. D. (2016). Using expert elicitation to estimate the impacts of plastic pollution on marine wildlife. Mar. Policy, 65, 107-114. doi: 10.1016/j.marpol.2015.10.014

Wilcox, C., Van Sebille, E., and Hardesty, B. D. (2015). Threat of plastic pollution to seabirds is global, pervasive, and increasing. Proc. Natl. Acad. Sci. U.S.A. 112, 11899-11904. doi: 10.1073/pnas.1502108112

Woodall, L. C., Sanchez-Vidal, A., Canals, M., Paterson, G. L. J., Coppock, R., Sleight, V., et al. (2014). The deep sea is a major sink for microplastic debris. R. Soc. Open Sci. 1:140317. doi: 10.1098/rsos.140317

Conflict of Interest Statement: The authors declare that the research was conducted in the absence of any commercial or financial relationships that could be construed as a potential conflict of interest.

The reviewer OG and handling Editor declared their shared affiliation, and the handling Editor states that the process nevertheless met the standards of a fair and objective review.

Copyright (c) 2017 Hardesty, Harari, Isobe, Lebreton, Maximenko, Potemra, van Sebille, Vethaak and Wilcox. This is an open-access article distributed under the terms of the Creative Commons Attribution License (CC BY). The use, distribution or reproduction in other forums is permitted, provided the original author (s) or licensor are credited and that the original publication in this journal is cited, in accordance with accepted academic practice. No use, distribution or reproduction is permitted which does not comply with these terms. 